\title{
Reprimo as a modulator of cell migration and invasion in the MDA-MB-231 breast cancer cell line
}

\author{
Kurt Buchegger ${ }^{1}$, Carmen $\| l i^{1}$, Ismael Riquelme ${ }^{1}$, Pablo Letelier ${ }^{2}$, Alejandro H. Corvalán ${ }^{3}$, Priscilla Brebi ${ }^{1}$, \\ Tim Hui-Ming Huang ${ }^{4}$ and Juan Carlos Roa ${ }^{5^{*}}$
}

\begin{abstract}
Background: Reprimo (RPRM), a highly glycosylated protein, is a new downstream effector of p53-induced cell cycle arrest at the G2/M checkpoint, and a putative tumor suppressor gene frequently silenced via methylation of its promoter region in several malignances. The aim of this study was to characterize the epigenetic inactivation and its biological function in BC cell lines.

Methods: The correlation between RPRM methylation and loss of mRNA expression was assessed in six breast cancer cell lines by methylation specific PCR (MSP), 5'-Aza-2'-deoxycytidine treatment and RT-PCR assays. MDA-MB-231 cells were chosen to investigate the phenotypic effect of RPRM in cell proliferation, cell cycle, cell death, cell migration and invasion.

Results: In the cancer methylome system (CMS) (web-based system for visualizing and analyzing genome-wide methylation data of human cancers), the $\mathrm{CpG}$ island region of RPRM (1.1 kb) was hypermethylated in breast cancer compared to normal breast tissue; more interesting still was that $E R a(+)$ tumors showed higher methylation intensity than ERa(-). Downregulation of RPRM mRNA by methylation was confirmed in MDA-MB-231 and BT-20 cell lines. In addition, overexpression of RPRM in MDA-MB-231 cells resulted in decreased rates of cell migration, wound healing and invasion in vitro. However, RPRM overexpression did not alter cell viability, phosphatidylserine (PS) translocation or G2/M cell cycle transition.
\end{abstract}

Conclusion: Taken together, these data suggest that RPRM is involved in decreased cell migration and invasion in vitro, acting as a potential tumor suppressor gene in the MDA-MB-231 cell line.

Keywords: Reprimo, MDA-MB-231, Migration, Invasion

\section{Background}

Breast cancer $(\mathrm{BC})$ is the second most common cancer in the world and by far the most frequent cancer among women. Approximately, 1.67 million new cancer cases were diagnosed in 2012 ( $25 \%$ of all cancers), being the second cause of cancer death in developed regions (198,000 deaths, $15.4 \%)$ [1].

\footnotetext{
*Correspondence: jcroas@gmail.com

${ }^{5}$ Department of Pathology, Advanced Center for Chronic Diseases (ACCDiS) (CITO), School of Medicine, Pontificia Universidad Católica de Chile, Santiago, Chile

Full list of author information is available at the end of the article
}

Loss of proliferation regulation and the activation of invasion and metastasis are considered hallmarks in many cancer types, including BC. These processes are tightly regulated within normal cells. A deregulation in proliferation may occur by several mechanisms, including direct expression of growth factor ligands and receptors by cancer cells or by induction of surrounding normal cells, which permits an uncontrolled proliferation of tumor cells. At this point, the role of tumor suppressor genes that limit growth and proliferation in cancer is important [2].

Cell migration plays a central role in a wide variety of biological phenomena in both normal physiology and 
pathophysiology. In a tumor setting, cell migration and invasion are the processes that allow malignant cells to change their position within tissue or between organs, penetrating tissue barriers such as the basement membrane, infiltrating the underlying interstitial tissue and spreading to the metastatic sites [3].

The associated cancer cells typically develop many alterations in morphology as well as in the cell-cell attachment and extracellular matrix to obtain the ability to dissociate intracellular adhesions and become motile. This process is usually driven by complex regulatory signaling cascades that temporarily and/or permanently alter the expression of several genes that reorganize the cytoskeletal network $[2,4,5]$.

In 2000, Ohki et al. [6] identified a new gene called Reprimo (latin for repress), a potential new gene p53-dependent tumor suppressor by using differential display polymerase chain reaction (PCR) in x-ray-irradiated mouse embryonic fibroblasts.

Reprimo (RPRM) is located at $2 \mathrm{q} 23$ and encodes a highly glycosylated protein that shows four bands $(16,21$, 23 and $40 \mathrm{kDa}$ ) found predominantly in the cytoplasm [6]. Nevertheless, in silico gene ontology analysis of its amino acid sequence show that RPRM is an integral component of cell membrane (URL: http://www.uniprot.org/ uniprot/Q9NS64). Overexpression of RPRM by adenovirus transfection induces G2 arrest by inhibiting both Cdc2 activity and nuclear translocation of Cdc2-cyclin B1 complex in mouse embryonic fibroblast, acting as a suppressor of cell cycle progression. Cyclin B1, a key component in the control of cell cycle progression from G2 to $\mathrm{M}$ phase, has been implicated in tumorigenesis and the development of malignancy. Overexpression of cyclin B1 promotes cell invasive growth and extravasation through the capillary endothelium [7]. Therefore, RPRM acts as mediator of cell cycle transition, blocking nuclear transition of Cdc2-Cyclin B1 complex [6]. RPRM may repress cyclin B1-Cdc2 activity, promoting cell cycle arrest at the G2/M checkpoint and/or suppressing metastatic potential, exerting a tumor suppressive activity [7].

$R P R M$ promoter methylation has been reported in several tumor cell lines and tumors including pancreas, head and neck, prostate, liver, gastric, renal and pituitary [8-16]. In gastric cancer, RPRM methylation has been detected frequently in plasma, promising to become a biomarker of the early stage of progression [13]. Furthermore, in esophageal cancer RPRM promoter methylation is significantly lower in chemoradiotherapy responders than in non-responders [17], and is predictive of a poor prognosis in pancreatic ductal carcinoma [10].

Nevertheless, in BC there have been no reports about whether $R P R M$ mRNA levels are altered by promoter methylation and whether act as a repressive mechanism of mRNA expression, or about the functional significance of the ectopic expression of RPRM in the MDA-MB-231 cell line. Therefore, we decided characterize the epigenetic inactivation and its biological function of $R P R M$ in $\mathrm{BC}$ cell lines.

\section{Results \\ Reprimo is differentially methylated between $B C$ and normal control sample tissues}

The cancer methylome system (CMS) website uses a computational analysis to calculate the average intensity of RPRM CpG island methylation (Start-End: 154042600-154043700, length: $1.1 \mathrm{~kb}$, Chromosome 2) between $B C$ (77) and normal control samples (10) (Fig. 1a). The calculated methylation intensity was higher in the $\mathrm{BC}$ group than in the normal control group (Fig. 1b; $\mathrm{P}<0.001)$. Moreover, we correlated the methylation data with clinic-pathological features, but there were no significant differences with any characteristic (data not shown). Nevertheless, when BC cases were classified into two groups: estrogen receptor positive $[E R \alpha(+)]$ and estrogen receptor negative $[E R \alpha(-)]$, we found higher methylation intensity in the $\mathrm{ER} \alpha(+)$ group (Fig. 1c; $\mathrm{P}<0.001)$. Unfortunately, we could not classify the $\mathrm{BC}$ tissues into other different molecular subtypes, such as Luminal A, Luminal B, Her2 and Basal-like, because data of the protein expression of Her2+ and Ki67 were incomplete. Based on these results, we decided to characterize the epigenetic inactivation and its biological function of $R P R M$ in $\mathrm{BC}$ cell lines.

\section{Reprimo transcript is downregulated in BC cell lines by promoter methylation}

To determine the methylation $(\mathrm{M})$ or unmethylated $(\mathrm{U})$ status of RPRM promoter, methylation specific polymerase chain reaction (MSP) technique was performed. The flanked region by primer in $5^{\prime}$-promoter region was described in previous reports $[8,18]$. The primers were tested using $100 \%$ methylated DNA and non-methylated DNA before to perform the experiment in cell lines (data not shown).

$R P R M$ promoter was methylated in 3/5 (MDAMB-231, BT-20 and HCC-1954) of the BC cell lines analyzed (Fig. 2a). Lost or repressed mRNA expression was found in 2/5 (MDA-MB-231 and BT-20) of BC cell lines (Fig. 2b). To validate MSP results, we performed a qMSP analysis, which revealed promoter methylation in MDAMB-231 and BT-20, the same cell lines with a repressed $R P R M$ expression (data not shown). After $5^{\prime}$ Aza-dC treatment, RPRM mRNA expression in MDA-MB-231 and BT-20 was restored (Fig. 2b). Therefore, we concluded that the transcriptional silencing of RPRM due to its promoter methylation in $\mathrm{BC}$. 


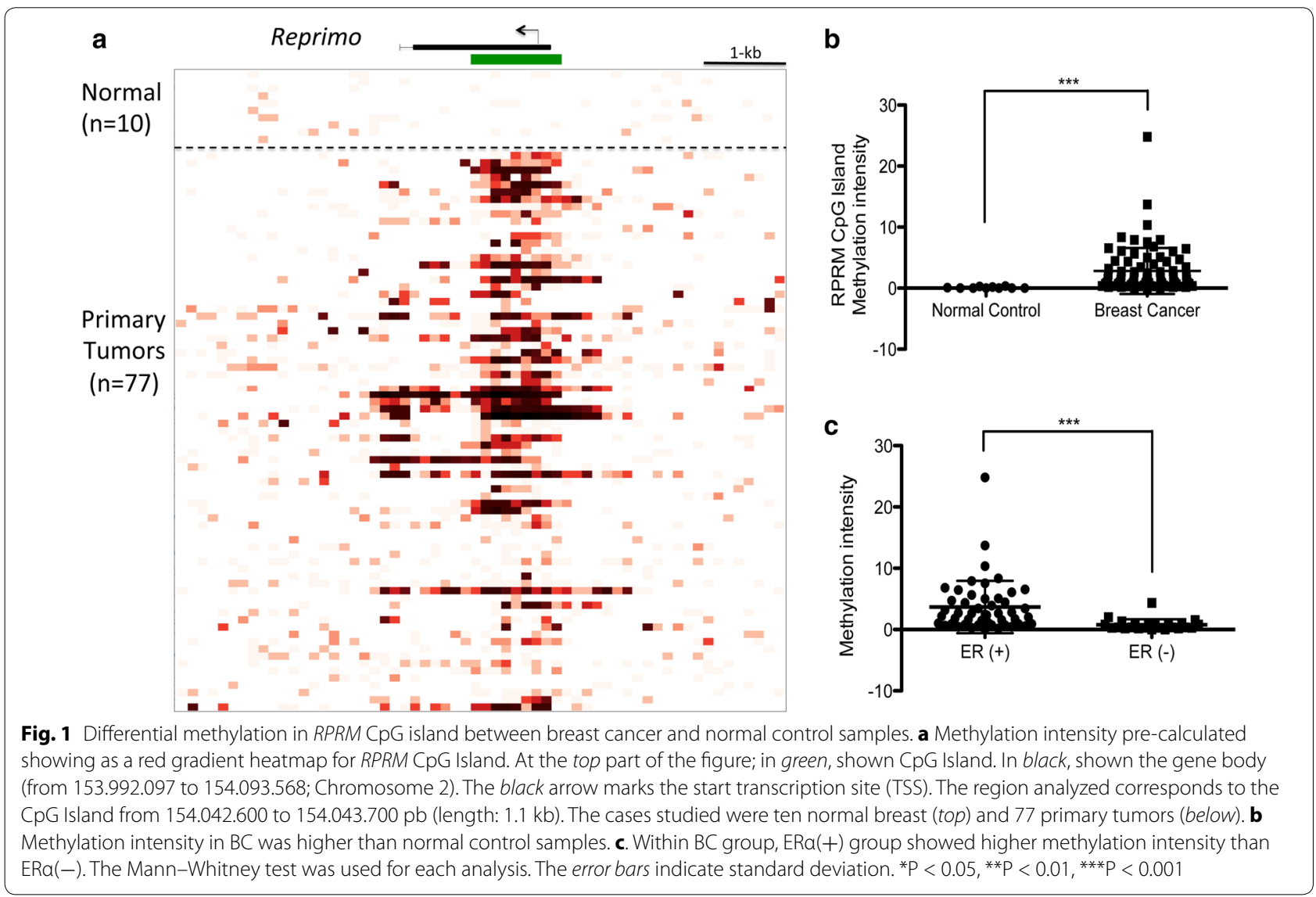

\section{Reprimo overexpression suppresses cell migration and invasiveness in MDA-MB-231}

MDA-MB-231 cells were transiently transfected either with pCMV6-empty or with pCMV containing the full-length cDNA of RPRM gene (pCMV-RPRM). MDA-MB-231 cells transfected with pCMV6-RPRM (MDA-MB-231-RPRM cells) showed an increase in mRNA and protein levels of RPRM, compared to pCMV6-empty (MDA-MB-231-pCMV6 cells) (Fig. 3a). We tested whether RPRM could alter cell migration and invasion by wound healing assay and assays based in boyden chamber with or without matrigel matrix. Results in transwell migration assays showed a decrease of MDAMB-231-RPRM cells migration in about $64.3 \%$ (35.7 \% of migrated cells) compared to MDA-MB-231-pCMV6 (Fig. 3b; $\mathrm{P}<0.0001$ ). To verify these results, we performed a wound-healing assay. On this regard, we found that $48 \mathrm{~h}$ post-scratch, the wound was completely closed in MDAMB-231-pCMV6 cells, while in MDA-MB-231-RPRM cells the wound remained open (Fig. 3c). To study the invasiveness potential of these treated cells, we perform an invasion assay using a Boyden chamber coated with matrigel. We found that effectively MDA-MB-231-RPRM cells migrated $51 \%$ less than MDA-MB-231-pCMV6 cells (Fig. 3d; $P<0.0001)$. In summary, transfected cells with RPRM-containing vector (MDA-MB-231-RPRM) exhibited significantly lower cell migration and invasion rate than those transfected with empty vector (MDAMB-231-pCMV6), confirming for first time that RPRM regulates cell migration and invasion in cancer cells, particularly in BC cells.

Reprimo overexpression failed to induce cell death and cell cycle arrest in MDA-MB-231 BC cells

There were no statistical differences in cell viability between cells expressing either a control vector (MDAMB-231-pCMV6) or RPRM (MDA-MB-231-RPRM) (Fig. 4a). To determine the functional consequences of $R P R M$ overexpression in regard to programmed cell death, an Annexin V (AV)/propidium iodide (PI) staining assay was performed in MDA-MB-231 cells at $48 \mathrm{~h}$ posttransfection. Overexpression of $R P R M$ slightly increased apoptosis and cell death, but these differences were not significant in compared with control-transfected cells (Fig. 4b). Flow cytometry analyses were grouped into three types of cell stages according to the Nomenclature Committee on Cell Death (2012): live cells (AV-/PI-), apoptotic cells $(\mathrm{AV}+/ \mathrm{PI}-)$ and death cells $(\mathrm{AV}+/ \mathrm{PI}+$, 


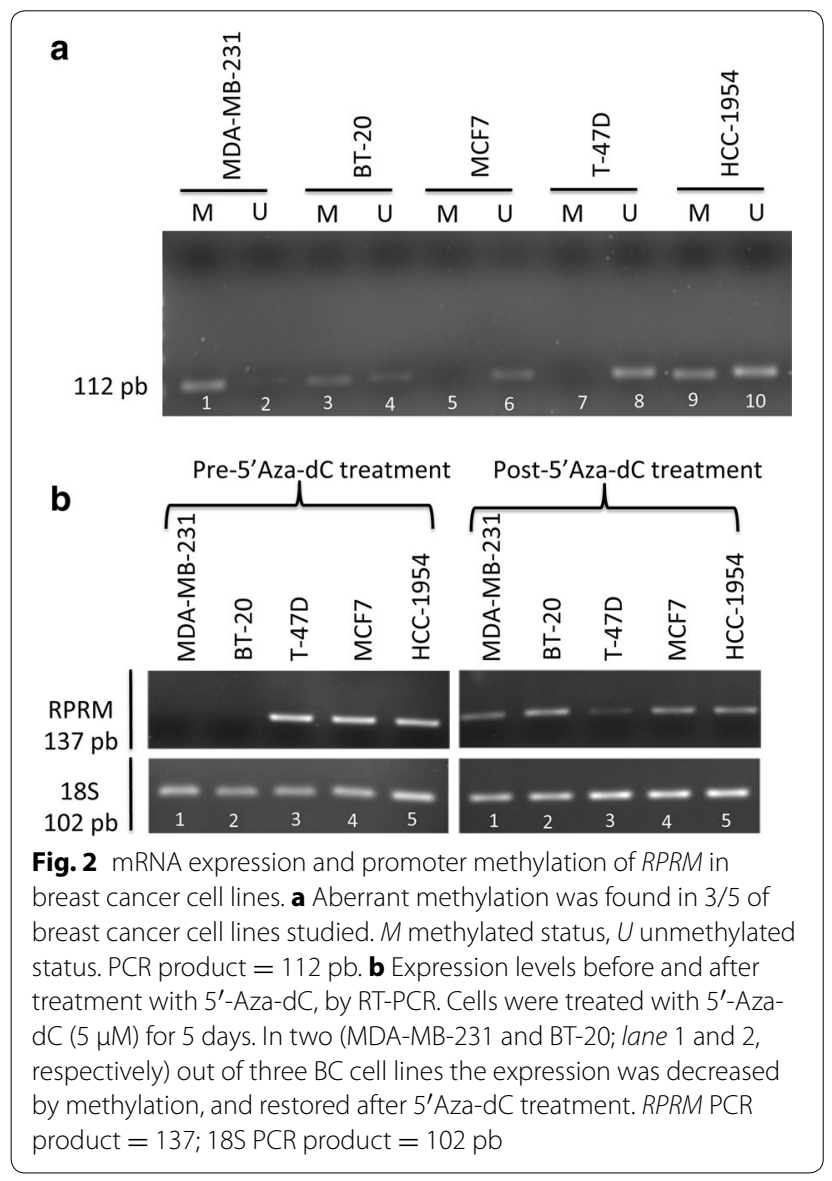

and $\mathrm{AV}-/ \mathrm{PI}+)$. The average percentage for apoptotic cells was $4.0 \%$ for RPRM and $2.5 \%$ for control cells. The average percentage for death cells was $6.8 \%$ for $R P R M$ and $3.7 \%$ for control cells. In summary, in terms of apoptotic cells and death cells, we confirmed that cell viability was not significantly decreased in MDA-MB-231-RPRM compared with MDA-MB-231-pCMV6.

Cells were synchronized by serum deprivation for cell cycle profiles; however, there were no changes in the percentages of cells in the $\mathrm{G} 2 / \mathrm{M}$ phase between MDA-MB-231-pCMV6 and MDA-MB-231-RPRM cells (Fig. 4c). Therefore, RPRM does not have a significant effect to alter G2/M in MDA-MB-231 cells.

\section{Discussion}

Reprimo is a potential p53-dependent tumor suppressor, located at 2q23 and encodes a highly glycosylated protein, located predominantly in the cytoplasm. It is believed to regulate the activity of the Cdc2-cyclin $\mathrm{B} 1$ complex by interfering with an as yet unknown checkpoint G2/M mechanism operating in the cytoplasm [6]. Several studies have shown that tumor suppressor genes that participate in cell cycle arrest are frequently inactivated through aberrant methylation in human malignances [19]. In this regard, RPRM promoter methylation has been found in several human cancers, including pancreas $[8,10,20]$, head and neck [9], esophagus [17, 21], prostate [11, 22], lung [23], kidney [16], pituitary [14] and gastric [13, $15,24]$. There have been no reports regarding methylation status or functional studies in BC. Using the CMS platform [25], we analyzed the methylation status of the $R P R M$ CpG island region (1.1 kb) in $\mathrm{BC}$ tissues, finding hypermethylation in cancer tissue but not in normal control samples. Moreover, methylation intensity was higher in $E R \alpha(+)$ than $E R \alpha(-)$ in the $B C$ group, suggesting that $R P R M$ methylation is linked to ER status. Similarly, Malik et al. proposed a repression of $R P R M$ gene transcription mediated by a tripartite interaction between $E R \alpha$, histone deacetylase 7 (HDAC7), and FoxA1 [26]. We decided characterize the epigenetic inactivation and its biological function of RPRM in $\mathrm{BC}$ cell lines.

MSP was performed on five $\mathrm{BC}$ cell lines, which revealed methylation of the promoter region of $R P R M$ in $3 / 5$ (MDA-MB-231, BT-20 and HCC-1954) lines analyzed. However, qMSP analysis showed promoter methylation in 2/5 lines (MDA-MB-231 and BT-20; data not shown). These two lines exhibited loss or repression of RPRM mRNA expression. When we treated these cell lines with 5'Aza-dC, mRNA expression was restored, indicating that methylation is the main mechanism of gene silencing of RPRM in the MDA-MB-231 and BT-20 cell lines. This phenomenon was also observed in esophageal adenocarcinoma and squamous carcinoma cell line OE33 and KYSE 110 [21], respectively, and in three renal cell carcinoma cell lines (KTCL26, SKRC18 and SKRC39) [16]. Interestingly, $R P R M$ is located at chromosome $2 \mathrm{q} 23.3$, a locus that often has allelic imbalance in BC [27]; nevertheless, we observed that loss or repression of mRNA expression was restored by $5^{\prime} \mathrm{Aza}-\mathrm{dC}$ treatment, concluding that there is probably no allelic imbalance of $2 \mathrm{q} 23$ involved in loss of $R P R M$ mRNA expression in these two cell lines.

Interestingly, only two cells lines (BT-20 and MDAMB-231) showed RPRM promoter methylation with mRNA expression loss, both of them ER $\alpha(-)$ cells. Surprisingly, in ER $\alpha(+)$ cells MCF7 and T47D the RPRM promoter was hypomethylated and presented mRNA expression in contrast to $\mathrm{ER} \alpha(+) \mathrm{BC}$ tissues results, likely because cells culture are not being exposed to estrogen as BC tissues.

In functional studies, we tested whether RPRM could be less viable and increase PS translocation in MDAMB-231 cells, as previously reported in gonadotrope and GH pituitary cells [14]. However, there were no differences between cells with $R P R M$ and the empty control. Also, we enquired as to whether RPRM could act as a G2/M phase cell cycle brake in MDA-MB-231 BC cells 


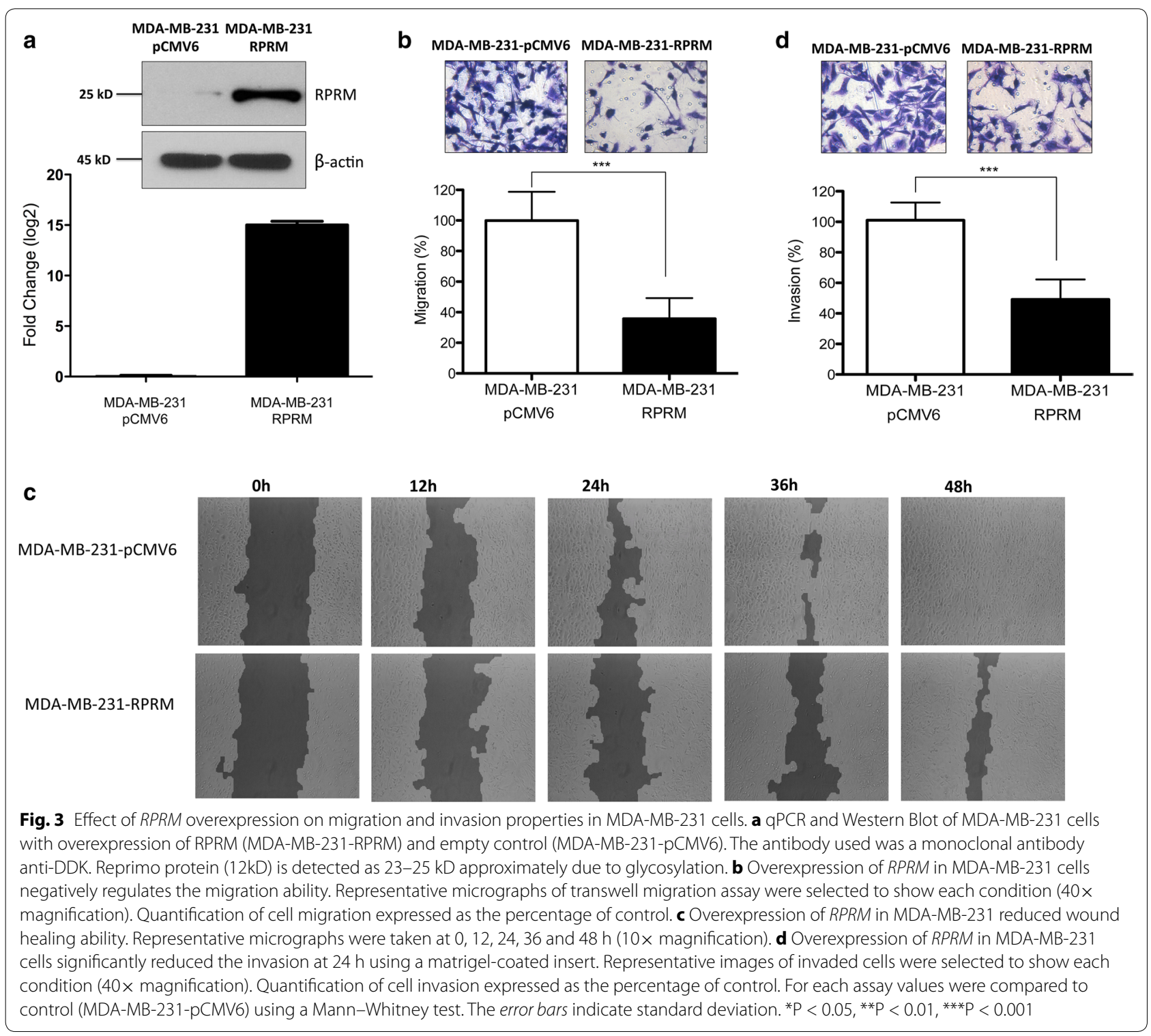

as previously reported in mouse embryonic fibroblast [6]. Unfortunately, $R P R M$ cannot significantly alter $\mathrm{G} 2 / \mathrm{M}$ in MDA-MB-231 cell line. Our results of cell cycle arrest are consistent with those in pituitary [14] and gastric tumors [15], suggesting that $R P R M$ may perform an alternative cell function in non-fibroblast derived cells, or even depending on tumor type.

In addition, we examined whether RPRM has a role in cell migration and invasion. In an immunohistochemistry study involving S100A2 and RPRM, Luo et al. found that loss of RPRM protein expression was significantly correlated with the depth of tumor invasion, lymphatic vessel invasion, and lymph node metastasis, suggesting tumor suppressor activity of RPRM in human clinical gastric tumor tissue [28]. In our study, we expressed $R P R M$ ectopically in MDA-MB-231 cells, finding a significant decrease in cell migration by transwell inserts and wound healing as well as a significant decrease in cell invasion by inserts with matrigel, supporting an important role in cell mobility and invasion in MDA-MB-231 cells.

These results are not consistent with previous results about the biology of $R P R M$. However, a previous study by Song et al. into cyclin B1 (a protein target of RPRM) demonstrated that, in addition to its known role in arresting the G2/M cell cycle phase, overexpression of cyclin B1 in human esophageal squamous cell carcinoma (ESCC) promotes cell invasive growth and extravasation through the capillary endothelium. Furthermore, in xenograft 

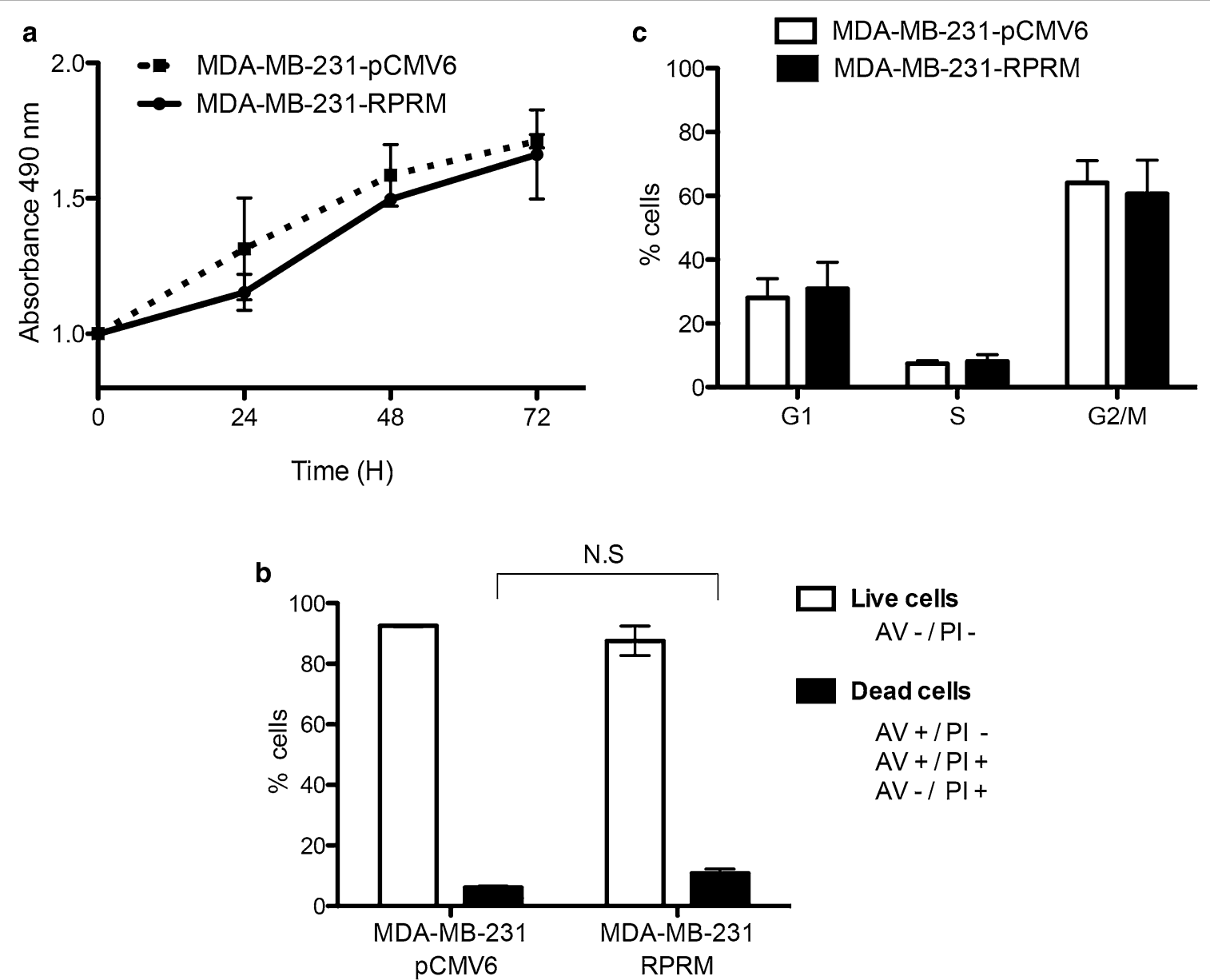

Fig. 4 Role of RPRM in cell death and cell cycle arrest in MDA-MB-231 cells. a Overexpression of RPRM in MDA-MB-231 cells did not decrease cell viability. b Ectopic expression of RPRM did not significantly increase cell death in MDA-MB-231 cells. c Modulating RPRM levels had no effect on progression of cell cycle phases. MDA-MB-231-pCMV6 was used as a control. For each experiment, RPRM mRNA and protein levels were confirmed by $\mathrm{qPCR}$ and Western blot with an anti-flag antibody, respectively

mice, overexpression of cyclin B1 is able to enhance lung metastasis in ESCC. Likewise, suppression of endogenous cyclin B1 inhibits the metastatic potential of ESCC to the lung. In addition, cyclin B1-induced ESCC metastasis appears to be linked to alteration of epithelial mesenchymal transition (EMT) molecules [7]. Given that $R P R M$ regulates the activity of the Cdc2-cyclin $\mathrm{B} 1$ complex, it is likely that the antagonist effect in cell migration and invasion is through cyclin B1 inactivation.

\section{Conclusion}

Our study was the first to report on the possible role of $R P R M$ in the modulation of cell migration and invasion process in vitro in $\mathrm{BC}$. Further investigation into the $R P R M$-regulated molecules is required, to clarify the mechanisms by which RPRM could exert tumor suppressive activity in migration and invasion capability.

\section{Methods}

\section{Cancer methylome system analysis}

The CMS is a web-based database application designed for the visualization, comparison and statistical analysis of human cancer-specific DNA methylation. The BC database was constructed with 77 breast tumors, 10 normal breast samples (mammary reduction) and $41 \mathrm{BC}$ cell lines. The datasets were obtained with the MBDCap-seq protocol, a technique used to capture methylated DNA by using a methyl-CpG binding domain (MBD) protein column followed by next-generation sequencing $[25,29]$. We performed comparative analyses of DNA methylation profiles between normal controls and BC samples, which were downloaded from the CMS. Then, by computational analysis the average intensity correlation of methylation of RPRM CpG Island (1.1 kb length) was calculated in these two 
groups. BC tissue samples were fresh frozen tissue with $\geq 70 \%$ tumor cellularity.

\section{Cell lines and transfections}

BC cell lines MDA-MB-231, BT-20, T-47D, MCF7 and HCC1954 were generously provided by Dr. Tim HuiMing Huang (University of Texas Health Science Center at San Antonio, TX). MDA-MB-231 and BT-20 were cultured in Dulbecco's Modified Eagle's medium (high glucose), T-47D and HCC1954 in Roswell Park Memorial Institute (RPMI) 1640 medium (Thermo Scientific HyClone, Logan, UT, USA) and MCF7 in Advanced Modified Eagle's medium (Invitrogen, Life Technologies corporation, Grand Island, NY, USA) supplemented with $10 \%$ fetal bovine serum, 10 units $/ \mathrm{mL}$ of penicillin and $10 \mathrm{mg} / \mathrm{mL}$ streptomycin (1\% penicillin/streptomycin, Thermo Scientific Hyclone). All five cell lines were incubated at $37{ }^{\circ} \mathrm{C}$ in a humidified atmosphere containing $5 \% \mathrm{CO}_{2}$ and subculture during the logarithmic phase.

To generate MDA-MB-231 transient-transfections, cells were transfected with pCMV6-RPRM-Myc-DDKtagged or pCMV6 (empty vector control) (OriGene Technologies, Inc), using Lipofectamine 2000 (Invitrogen) according to the manufacturer's instructions. All experiments were carried out in technical and biological triplicate. The success of transfection was confirmed by quantitative real-time PCR and western blot.

\section{5'-Aza-2'-deoxycytidine treatment}

Breast cancer cell lines were incubated in culture medium with the demethylating agent 5-Aza-2'-deoxycytidine at a concentration of $5 \mu \mathrm{M}$ for 5 days. Fresh media were added at 24 and $72 \mathrm{~h}$. Cells were harvested and RNA was extracted at day 5 [16].

\section{Real time PCR}

Total cell RNA was isolated from cells using the TRIzol reagent (Life Technologies) according to the manufacturer's instructions. First-strand cDNA was prepared from $1 \mu \mathrm{g}$ of cell RNA in a total reaction volume of $20 \mu \mathrm{L}$ using M-MLV reverse transcriptase $200 \mathrm{U} / \mu \mathrm{l}$ (Promega Corp., Madison, WI) at $42{ }^{\circ} \mathrm{C}$ for $60 \mathrm{~min}$. The resulting cDNA was subsequently amplified by PCR using the Brilliant II Ultra-Fast SYBR ${ }^{\circledR}$ Green qPCR Master Mix according to the manufacturer's protocol on the Stratagene Mx-3000p real-time PCR system (Agilent Technologies Inc., Santa Clara, CA). Relative fold levels were determined using the $2^{-\Delta \Delta C T}$ method, with $18 \mathrm{~S}$ used as housekeeping control. The primer pairs used are detailed in Table 1.

\section{DNA extraction}

Genomic DNA from cells was extracted using phenol/ chloroform and absolute ethanol DNA precipitation. The quantity and quality of extracted DNA were assessed by measuring the samples in a NanoDrop 1000 spectrophotometer (Thermo Fisher Scientific Inc., Waltham, MA).

\section{Sodium bisulfite modification}

A total of $1 \mu \mathrm{g}$ of genomic DNA was modified with sodium bisulfite using the EZ DNA Methylation ${ }^{\text {TM }}$ Bisulfite Kit (Zymo Research, Irvine, CA) following the manufacturer's protocol. Bisulfite-converted DNA was stored at $-80^{\circ} \mathrm{C}$ until use.

\section{Methylation-specific PCR (MSP)}

$R P R M$ promoter was amplified from bisulfite-converted DNA using specific primers for methylated and unmethylated DNA, obtained from a previous report (Sato N et al. [8]). Primer sequences and annealing temperature are provided in Table 1. Bisulfite-modified genomic

Table 1 Primer and probe sequences used in this study

\begin{tabular}{llll}
\hline ID & Sequences $\left(\mathbf{5}^{\prime} \mathbf{-}>\mathbf{3}^{\prime}\right.$ ) & PCR product (pb) & References \\
\hline RPRM (forward) & CTGCGATTTGAACGGGGTGAGT & 137 & - \\
RPRM (reverse) & GCGTAAACCGTGCAGTCACGA & 137 & - \\
RPRM-M (forward) & GCGAGTGAGCGTTTAGTTC & 120 & Sato et al. [8] \\
RPRM-M (reverse) & TACCTAAAACCGATTCATCG & 120 & Sato et al. [8] \\
RPRM-U (forward) & TTGTGAGTGAGTGTTAGTTTG & 113 & Sato et al. [8] \\
RPRM-U (reverse) & TAATTACCTAAACCAAATTCATC & 113 & Sato et al. [8] \\
B-actin-M (forward) & TGGTGATGGAGGAGGTTAGTAAGT & 133 & Moon et al. [30] \\
B-actin-M (reverse) & AACCAATAAAACCTACTCCTCCCTTAA & 133 & Moon et al. [30] \\
RPRM (probe qMSP) & /56-FAM/TT CGC GTC G/ZEN/T TCG CGG CGTTCG TT/3IABkFQ/ & 120 & - \\
B-actin (probe qMSP) & /56-FAM/AC CAC CAC C/ZEN/C AAC ACA CAA TAA CAA ACA CA/3IABkFQ/ & 133 & Moon et al. [30] \\
\hline
\end{tabular}

$M$ methylated, $U$ unmethylated 
DNA was amplified by PCR, the cycle of which was: (a) $95{ }^{\circ} \mathrm{C}$ for $5 \mathrm{~min}$; (b) 35 cycles: $95{ }^{\circ} \mathrm{C} 30 \mathrm{~s}, 59^{\circ} \mathrm{C} 30 \mathrm{~s}$, and $72{ }^{\circ} \mathrm{C} 30 \mathrm{~s}$; (c) $72{ }^{\circ} \mathrm{C} 5 \mathrm{~min}$ for a final extension. As a positive control $100 \%$ methylated DNA was used (Zymo Research, Irvine, CA). PCR mix without DNA was used as a blank. PCR products were analyzed by electrophoresis in $1.5 \%$ agarose gel and visualized by gel red staining (Biotium, Hayward, CA) under UV light.

\section{Quantitative methylation-specific PCR (qMSP)}

To quantify the methylation level of Reprimo, quantitative methylation-specific PCR (qMSP) was performed. Amplification reactions were carried out in triplicate in a volume of $20 \mu \mathrm{L}$ that contained $1 \mu \mathrm{L}$ of bisulfite-modified DNA; $300 \mathrm{nM}$ of each primer; $50 \mathrm{nM}$ probe (Table 1); $0.375 \mathrm{U}$ platinum Taq polymerase (Invitrogen); $100 \mu \mathrm{M}$ of dNTPs; $100 \mathrm{nM}$ ROX dye reference (Invitrogen); $8.3 \mathrm{mM}$ ammonium sulfate; $33.5 \mathrm{mM}$ Trizma (Sigma, St. Louis, MO); $3.35 \mathrm{mM}$ magnesium chloride; $5 \mathrm{mM}$ mercaptoethanol; and $0.05 \%$ DMSO [30]. Amplifications were carried out using the following profile: $95{ }^{\circ} \mathrm{C}$ for $10 \mathrm{~min}$ followed by 40 cycles at $95^{\circ} \mathrm{C}$ for $30 \mathrm{~s}, 59^{\circ} \mathrm{C}$ for $30 \mathrm{~s}$ and $72{ }^{\circ} \mathrm{C}$ for $30 \mathrm{~s}$. Amplification reactions were carried out in 96-well plates in the Mx3000P QPCR System (Stratagene). Each plate included DNA samples, positive control (100\% methylated DNA, Zymo Research) and water blanks. The relative level of methylated DNA for $R P R M$ was determined as a ratio of methylation-specific PCR-amplified gene to $\beta$-actin (reference gene) and then multiplied by 1000 for easier tabulation (average value of triplicates of the study gene divided by the average value of triplicates of $\beta$-actin $\times 1000)[30,31]$.

\section{Western blot}

$2 \times 10^{5}$ MDA-MB-231 cells were transiently transfected with pCMV6-RPRM-Myc-DDK-tagged or pCMV6 (empty vector control) (OriGene Technologies, Inc), using Lipofectamine 2000 (Invitrogen) according to the manufacturer's instructions. Cells were harvested and whole-cell lysates were extracted using RIPA buffer (50 mM Tris, pH 7.2; 150 mM NaCl; 1 \% Triton X-100; and $0.1 \%$ SDS).

With Protease and Phosphatase Inhibitor Cocktail Kit (Sigma Aldrich). Protein concentrations were determined using Pierce BCA protein assay kit (Pierce, Thermo Fisher Scientific Inc, Rockford, IL, USA) according to the manufacturer's instructions. Equal amounts of total cellular protein $(40 \mu \mathrm{g})$ were separated by sodium dodecyl sulfate-polyacrylamide gel electrophoresis in 4-12\% NuPAGE ${ }^{\circledR}$ Bis-Tris Precast Gels (Novex, Life Technologies Corporation) and electrotransferred to polyvinylidene difluoride membranes (Immobilon ${ }^{\circledR}-\mathrm{P}$ membrane, Millipore, Bedford, MA, USA). The membranes were blocked with $1 \times$ Tris-buffered saline containing $0.05 \%$ Tween (TBST) and $5 \%$ fat-free milk for $1 \mathrm{~h}$ at room temperature. Primary antibodies anti-DDK (Origene technologies; cat. № TA50011) and anti $\beta$-actin (Cell Signalling; cat.No 13E5) were diluted 1:2,000 and 1:5,000, respectively, in TBST/3\% BSA, the membranes were incubated in primary antibodies at $4{ }^{\circ} \mathrm{C}$ overnight. The Membranes were washed three times in TBST for $10 \mathrm{~min}$. Both anti-mouse and anti-rabbit peroxidaseconjugated secondary antibody (Santa Cruz) were diluted in 1:20,000 in TBST $1 \mathrm{X}$ and incubates the membrane for $1 \mathrm{~h}$ at room temperature. The membranes were washed as above and visualized using SuperSignal West Pico (Pierce) according to the manufacturer's protocol.

\section{Viability assays}

Cell viability in transfected MDA-MB-231 cells was determined using the CellTiter 96 AQueous one solution (Promega). Five thousand MDA-MB-231cells were seeded in a 96-well plate (four replicates for each condition) and allowed to attach overnight. Transfection was performed $24 \mathrm{~h}$ later, using Lipofectamine 2000 (Invitrogen) according to the manufacturer's instructions. Cells were incubated for 24,48 and $72 \mathrm{~h}$ after transfection. Control wells contained only cell-free medium. Twenty microliters of CellTiter MTS solution were added to each well, and plates were incubated for $1 \mathrm{~h}$ at $37^{\circ} \mathrm{C}$. Absorbance was measured at $490 \mathrm{~nm}$.

\section{Apoptosis analysis}

To study cell death from within transfected MDA-MB-231 cells to the outer leaflet of the plasma membrane, we used the Alexa Fluor 488 Annexin V/Dead Cell Apoptosis Kit (Life Technologies), staining according to the manufacturer's instructions, and analyzed it by flow cytometer (FACs Canto II, Becton-Dickinson). A total of $2.5 \times 10^{5}$ MDA-MB-231 cells were plated in a 6-multiwell plate (two replicates of each condition) and allowed to attach overnight. Transfection was performed $24 \mathrm{~h}$ later, using Lipofectamine ${ }^{\circledR} 2000$ (Invitrogen) following the manufacturer's protocol. Cells were incubated for $48 \mathrm{~h}$ post-transfection. Positive control cells were treated with $5 \%$ DMSO for $24 \mathrm{~h}$. Wild-type cells were used as a negative control.

\section{Cell cycle analysis}

MDA-MB-231 $\left(2.5 \times 10^{5}\right.$ cells per well $)$ cells were plated in a 6-multiwell plate (two replicates of each condition) and allowed to attach overnight. Cells were synchronized by starvation in serum-free media for $24 \mathrm{~h}$. Immediately, transient transfection was performed using Lipofectamine ${ }^{\circledR} 2000$ (Invitrogen). Cells were incubated for $48 \mathrm{~h}$ post-transfection in complete media. After incubation period, the cells were trypsinized, re-suspended, 
fixed (ethanol $70 \%$ for $2 \mathrm{~h}$ at $4{ }^{\circ} \mathrm{C}$ ) and finally stained with PI solution $(0.1 \%(\mathrm{v} / \mathrm{v})$ Triton X-100, $10 \mu \mathrm{g} / \mathrm{mL}$ PI, and $100 \mathrm{ug} / \mathrm{mL}$ DNase-free RNase A in PBS). Cell cycle profiles were gathered using a Flow cytometer (FACs Canto II, Becton-Dickinson) at the Universidad de La Frontera Scientific and Technological Bioresource Nucleus (BIOREN).

\section{Cell migration}

A total of $5 \times 10^{4}$ transient MDA-MB-231 transfected cells were suspended in $300 \mu \mathrm{l}$ of serum-free DMEM medium and seeded into the upper chamber of each insert (24-well insert; pore size, $8 \mu \mathrm{m}$; BD Biosciences). Then, $500 \mu \mathrm{L}$ of DMEM containing $10 \%$ FBS were added to a 24-well plate. After incubation at $37{ }^{\circ} \mathrm{C}$ for $12 \mathrm{~h}$, migrated cells were washed (twice with DPBS), fixed (Methanol $100 \%$ ) and stained for $15 \mathrm{~min}$ in crystal violet solution ( $0.5 \%$ crystal violet in $25 \%$ methanol/DPBS). Cells that did not migrate to the lower compartment were removed with a cotton swab. Each insert was photographed in five random fields at a magnification of $40 \times$. Quantification is expressed as the percentage of area covered with migrated cells by using Image J software (Wayne Rasband, National Institute of Health, USA).

\section{Wound healing}

A total of $1 \times 10^{5}$ MDA-MB-231 cells were plated in a 24 multi-well plate. Transient transfection was performed after $24 \mathrm{~h}$. Cells were allowed to form a confluent monolayer in a 24-well plate before wounding. A sterilized pipette tip was used to generate wounding across the cell monolayer, and the debris was washed with PBS. Cells migrating into the wounded area were visualized and photographed under an inverted microscope at varying intervals. A total of six areas were selected randomly in each condition and photographed at a magnification of $10 \times$.

\section{Cell invasion}

MDA-MB-231 cells were transfected with pCMV6-RPRM or pCMV6 vector using Lipofectamine 2000 (Invitrogen), following the manufacturer's protocol. Serum-induced cell invasion were performed at $37^{\circ} \mathrm{C}$ for $24 \mathrm{~h}$ using a 24-well transwell insert (24-well insert; pore size, $8 \mu \mathrm{m}$; BD Biosciences) coated with $30 \mu \mathrm{g}$ of matrigel (BD Biosciences). $5 \times 10^{4}$ cells suspended in $200 \mu \mathrm{l}$ serum-free medium were seeded into the upper chamber and $600 \mu \mathrm{l}$ complete medium into the lower chamber. After $24 \mathrm{~h}$, the upper surface of the insert was wiped gently with a cotton swab to remove non-migrating cells. Cells that migrated and invaded through the membrane were stained with crystal violet solution ( $0.5 \%$ crystal violet in $25 \%$ methanol/DPBS), and photographed by a microscope with a camera in five random fields at a magnification of $40 \times$. Quantification is expressed as the percentage of area covered with migrated cells by using Image software (Wayne Rasband, National Institute of Health, USA).

\section{Statistical analysis}

Data were analyzed by a Mann-Whitney test, KruskalWallis test and two-way ANOVA with Bonferroni's multiple comparisons test using GraphPad Prism software (San Diego, CA). Values were expressed as mean \pm SD. Values of $\mathrm{P}<0.05$ were considered statistically significant.

\section{Additional data}

The data supporting the result about RPRM methylation in $\mathrm{BC}$ tissues and cell lines were obtained from CMS website available in http://cbbiweb.uthscsa.edu/ KMethylomes/.

\section{Abbreviations}

RPRM: Reprimo; CMS: cancer methylome system; PCR: polymerase chain reaction; RT-PCR: retrotranscriptase polymerase chain reaction; qPCR: quantitative polymerase chain reaction; $B C$ : breast cancer; ER: estrogen receptor; PR: progesterone receptor; Her2: human epidermal receptor 2; MSP: methylation specific polymerase chain reaction; qMSP: quantitative methylation specific polymerase chain reaction; MTS: 3-(4,5-dimethylthiazol-2-yl)-5-(3carboxymethoxyphenyl)-2-(4-sulfophenyl)-2H-(tetrazolium) inner salt; PS: phosphatidilserine.

\section{Authors' contributions}

$\mathrm{KB}$ carried out the experiments and figures. $\mathrm{Cl}, \mathrm{IR}$ and $\mathrm{PL}$ participated in the design of the study and helped to draft the manuscript. AC, PB, TH and JCR conceived of the study, participated in its designed, and supervised the study. All authors read and approved the final manuscript.

\section{Author details}

1 Department of Pathology, Molecular Pathology Laboratory BIOREN-CEGIN, School of Medicine, Universidad de La Frontera, Temuco, Chile. ${ }^{2}$ School of Health Sciences, Universidad Católica de Temuco, Temuco, Chile. ${ }^{3}$ Centre for Translational Research in Oncology (CITO) and Department of Hematology and Oncology, Pontificia Universidad Catolica de Chile, Santiago, Chile. ${ }^{4}$ Department of Molecular Medicine/Institute of Biotechnology, University of Texas Health Science Center at San Antonio, STRF, Room 225, 7703 Floyd Curl Drive, San Antonio, TX 78229, USA. ${ }^{5}$ Department of Pathology, Advanced Center for Chronic Diseases (ACCDiS) (CITO), School of Medicine, Pontificia Universidad Católica de Chile, Santiago, Chile.

\section{Acknowledgements}

We thank so much PhD. Tim Hui-Ming Huang and his research team for their help into this work. This works was supported through Chilean government scholarship grants such as: CONICYT Scholarship No 21100814 , CONICYT support scholarship for doctoral thesis work No 24121558, Becas Chile grant of internship No 75130093, Project CORFO-CEGIN 09CN14-5960 and C.I. supported by Project FONDECYT Post-Doctoral No 3130630.

\section{Competing interests}

The authors declare that they have no competing interests.

Received: 24 September 2015 Accepted: 8 January 2016

Published online: 22 January 2016

\section{References}

1. Ferlay J, Soerjomataram I, Ervik M, Dikshit R, Eser S, Mathers C, et al. GLOBOCAN 2012 v1.0, Cancer Incidence and Mortality Worldwide: IARC CancerBase. No. 11 [Internet]. Lyon Fr. Int. Agency Res. Cancer. 2013. http://globocan.iarc.f. 
2. Hanahan D, Weinberg RA. Hallmarks of cancer: the next generation. Cell. 2011;144:646-74.

3. Kramer N, Walzl A, Unger C, Rosner M, Krupitza G, Hengstschläger M, et al. In vitro cell migration and invasion assays. Mutat Res. 2013;752:10-24.

4. Friedl P, Wolf K. Tumour-cell invasion and migration: diversity and escape mechanisms. Nat Rev Cancer. 2003;3:362-74.

5. Li L, Lu Y. Inhibition of hypoxia-induced cell motility by p16 in MDAMB-231 breast cancer cells. J Cancer. 2010;1:126-35.

6. Ohki R, Nemoto J, Murasawa H, Oda E, Inazawa J, Tanaka N, et al. Reprimo, a new candidate mediator of the p53-mediated cell cycle arrest at the G2 phase. J Biol Chem. 2000;275:22627-30.

7. Song Y, Zhao C, Dong L, Fu M, Xue L, Huang Z, et al. Overexpression of cyclin B1 in human esophageal squamous cell carcinoma cells induces tumor cell invasive growth and metastasis. Carcinogenesis. 2008;29:307-15.

8. Sato N, Fukushima N, Maitra A, Matsubayashi H, Yeo CJ, Cameron JL, et al. Discovery of novel targets for aberrant methylation in pancreatic carcinoma using high-throughput microarrays. Cancer Res. 2003;63:3735-42.

9. Wong TS, Kwong DL-W, Sham JS-T, Wei WI, Yuen AP-W. Methylation status of Reprimo in head and neck carcinomas. Int J Cancer. 2005;117:697.

10. Sato N, Fukushima N, Matsubayashi H, lacobuzio-Donahue CA, Yeo CJ, Goggins M. Aberrant methylation of Reprimo correlates with genetic instability and predicts poor prognosis in pancreatic ductal adenocarcinoma. Cancer. 2006;107:251-7.

11. Ellinger J, Haan K, Heukamp LC, Kahl P, Büttner R, Müller SC, et al. CpG island hypermethylation in cell-free serum DNA identifies patients with localized prostate cancer. Prostate. 2008;68:42-9.

12. Nishida N, Nagasaka T, Nishimura T, Ikai I, Boland CR, Goel A. Aberrant methylation of multiple tumor suppressor genes in aging liver, chronic hepatitis, and hepatocellular carcinoma. Hepatology. 2008;47:908-18.

13. Bernal C, Aguayo F, Villarroel C, Vargas M, Díaz I, Ossandon FJ, et al. Reprimo as a potential biomarker for early detection in gastric cancer. Clin Cancer Res. 2008;14:6264-9.

14. Xu M, Knox AJ, Michaelis KA, Kiseljak-Vassiliades K, Kleinschmidt-DeMasters BK, Lillehei KO, et al. Reprimo (RPRM) is a novel tumor suppressor in pituitary tumors and regulates survival, proliferation, and tumorigenicity. Endocrinology. 2012;153:2963-73.

15. Ooki A, Yamashita K, Yamaguchi K, Mondal A, Nishimiya H, Watanabe M. DNA damage-inducible gene, reprimo functions as a tumor suppressor and is suppressed by promoter methylation in gastric cancer. Mol Cancer Res. 2013;11:1362-74.

16. Morris MR, Ricketts C, Gentle D, Abdulrahman M, Clarke N, Brown M, et al. Identification of candidate tumour suppressor genes frequently methylated in renal cell carcinoma. Oncogene. 2010;29:2104-17.

17. Hamilton JP, Sato F, Greenwald BD, Suntharalingam M, Krasna MJ, Edelman MJ, et al. Promoter methylation and response to chemotherapy and radiation in esophageal cancer. Clin Gastroenterol Hepatol. 2006;4:701-8.
18. Saavedra K, Valbuena J, Olivares W, Marchant MJ, Rodríguez A, TorresEstay $V$, et al. Loss of expression of Reprimo, a p53-induced cell cycle arrest gene, correlates with invasive stage of tumor progression and p73 expression in gastric cancer. PLoS One. 2015;10(5):e0125834.

19. Esteller M. CpG island hypermethylation and tumor suppressor genes: a booming present, a brighter future. Oncogene. 2002;21:5427-40.

20. Sato N, Goggins M. The role of epigenetic alterations in pancreatic cancer. J Hepatobiliary Pancreat Surg. 2006;13(4):286-95.

21. Hamilton JP, Sato F, Jin Z, Greenwald BD, Ito T, Mori Y, et al. Reprimo methylation is a potential biomarkerof Barrett's-associated esophageal neoplastic progression. Clin Cancer Res. 2006;12:6637-42.

22. Ellinger J, Bastian PJ, Jurgan T, Biermann K, Kahl P, Heukamp LC, et al. CpG Island hypermethylation at multiple gene sites in diagnosis and prognosis of prostate cancer. Urology. 2008;71:161-7.

23. Yoshino M, Suzuki M, Tian L, Moriya Y, Hoshino H, Okamoto T, et al. Promoter hypermethylation of the p16 and Wif-1 genes as an independent prognostic marker in stage IA non-small cell lung cancers. Int. J. Oncol. 2009;35:1201-9.

24. Schneider BG, Peng D-F, Camargo MC, Piazuelo MB, Sicinschi LA, Mera R, et al. Promoter DNA hypermethylation in gastric biopsies from subjects at high and low risk for gastric cancer. Int J Cancer. 2010;127:2588-97.

25. Gu F, Doderer MS, Huang YW, Roa JC, Goodfellow PJ, Kizer EL, et al. CMS: A Web-Based System for Visualization and Analysis of Genome-Wide Methylation Data of Human Cancers. PLoS One. 2013;8:e60980.

26. Malik S, Jiang S, Garee JP, Verdin E, Lee AV, O'Malley BW, et al. Histone deacetylase 7 and FoxA1 in estrogen-mediated repression of RPRM. Mol Cell Biol. 2010;30:399-412.

27. Piao Z, Lee KS, Kim H, Perucho M, Malkhosyan S. Identification of novel deletion regions on chromosome arms $2 q$ and $6 p$ in breast carcinomas by amplotype analysis. Genes Chromosomes Cancer. 2001;30:113-22.

28. Luo J, Zhu Y, Yang G, Gong L, Wang B, Liu H. Loss of Reprimo and S100A2 expression in human gastric adenocarcinoma. Diagn Cytopathol. 2011:39:752-7.

29. Rauch T, Li H, Wu X, Pfeifer GP. MIRA-assisted microarray analysis, a new technology for the determination of DNA methylation patterns, identifies frequent methylation of homeodomain-containing genes in lung cancer cells. Cancer Res. 2006;66:7939-47.

30. Brebi P, Hoffstetter R, Andana A, Ili CG, Saavedra K, Viscarra T, et al. Evaluation of ZAR1 and SFRP4 methylation status as potentials biomarkers for diagnosis in cervical cancer: exploratory study phase I. Biomarkers. 2014;19:181-8.

31. Moon H-S, Park WI, Choi E-A, Chung H-W, Kim S-C. The expression and tyrosine phosphorylation of E-cadherin/catenin adhesion complex, and focal adhesion kinase in invasive cervical carcinomas. Int J Gynecol Cancer. 2003;13:640-6.

\section{Submit your next manuscript to BioMed Central and we will help you at every step:}

- We accept pre-submission inquiries

- Our selector tool helps you to find the most relevant journal

- We provide round the clock customer support

- Convenient online submission

- Thorough peer review

- Inclusion in PubMed and all major indexing services

- Maximum visibility for your research

Submit your manuscript at www.biomedcentral.com/submit

\section{Biomed Central}

